\title{
Histórico das bibliotecas escolares no Estado do Paraná
}

\author{
Historical path of school libraries in the State of Paraná
}

Leda Maria Araújo Lima

Mestranda em Ciência da Informação pela Universidade Estadual de Londrina - UEL. Gestora cultural - serviços de biblioteconomia na Prefeitura Municipal de Londrina. E-mail: le-araujo@hotmail.com

\begin{abstract}
Rovilson José Silva
Doutorado sanduíche em Educação pela Universidade Estadual Paulista Júlio de Mesquita Filho/campus Marília e Universidade Autônoma de Barcelona. Professor Adjunto do Departamento de Educação da Universidade Estadual de Londrina - UEL. E-mail: rovilson@uel.br
\end{abstract}

\begin{abstract}
Resumo
O presente artigo tem por objetivo apresentar o histórico das bibliotecas escolares no Estado do Paraná, sua evolução desde o século XVII ao século XXI. É uma pesquisa de cunho bibliográfico, alicerçada na investigação, identificação, leitura e análise de escritas, documentos, leis e decretos, que ocorreram ao longo do tempo neste Estado. A pesquisa buscou descrever e analisar o processo de surgimento das bibliotecas escolares dentro do sistema de ensino e a estruturação de bibliotecas nesses espaços, evolução, conquistas e avanços. Esta Instituição, embora atualmente esteja garantida em lei, ainda requer reflexões mais profundas e amadurecimento. Pretende-se com este trabalho apresentar a historiografia e suscitar discussões e contribuições para futuros estudos acerca dessa temática.
\end{abstract}

Palavras-chave: Biblioteca Escolar no Paraná; Historiografia; Ensino no Paraná.

\begin{abstract}
This article aims to briefly present the history of schools and school libraries in the state of Paraná, its evolution since the seventeenth century to the twenty-first century. It is a bibliographical research, grounded in research, identification, reading and analysis of written documents, laws and decrees, which have occurred over time in this state. The research aims to describe and analyze the process of emergence of the school libraries system in Paraná and the structuring of libraries in these spaces, developments, achievements and progress. This institution despite being guaranteed by law still requires deeper reflection and maturation. The aim of this work was to present the history and raise discussion and contributions for future studies on this subject.
\end{abstract}

Keywords: School Library in Paraná; Historiography; Education in Paraná. 


\section{Introdução}

Nas últimas décadas a biblioteca escolar tem sido discutida nas áreas diretamente envolvidas com ela, em especial, destacamos a Biblioteconomia e a Educação. Cada vez mais, tem-se a clareza que, na perspectiva de se formar leitor, não se poderá ignorar a existência ou a inexistência desta instituição no ambiente escolar.

Reconhecido sua importância pela UNESCO desde 2000, essa instituição ainda requer amadurecimento e, principalmente, implantação no sistema de ensino do Brasil, cuja deficiência é grande, conforme demonstra a pesquisa "Avaliação das Bibliotecas Escolares no Brasil”, que 2/3 das 162.819 escolas de educação básica do país não possuem biblioteca.

Em 2010 foi outorgada a Lei 12.244 que dispõe sobre a universalização da Biblioteca Escolar que deveria, a partir daquela data, acontecer em todas as escolas do país na próxima década. Nesse aspecto, se a lei está vigendo, o mesmo não se pode dizer em relação ao plano efetivo para a construção de bibliotecas nas 108.546 escolas do país (BRASIL, 2011).

Em busca de compreender o processo no âmbito mais local, apresentamos o resultado de uma pesquisa de revisão de literatura acerca do desenvolvimento histórico das bibliotecas escolares no estado do Paraná, desde antes de sua emancipação política aos dias de hoje.

A pesquisa utilizou-se da revisão bibliográfica, documentos históricos e leis que regeram o país e o estado ao longo desse processo histórico, do século XVII ao século XXI e evidencia conquistas e dificuldades que o Paraná encontrou em toda sua trajetória política para estruturação e legitimação das bibliotecas nas escolas.

\section{Escola e biblioteca no Paraná: do século XVII ao século XIX}

Paraná, região inicialmente habitada por indígenas, pertencentes ao grupo linguístico Jê e Tupi- Guarani, desde o século XVII foi conhecida e designada como a Quinta Comarca subordinada e pertencente à província de São Paulo. Os paulistas vinham para a região, com a intenção de explorar e buscar ouro e foram eles que deram origem ao primeiro povoado, que se tornou vila em 1.648 com o nome de Nossa Senhora do Rosário de Paranaguá e somente na década seguinte foi criada a segunda vila, a vila de Nossa Senhora da Luz dos Pinhais de Curitiba, que se tornou município em 1.683 (TRINDADE; ANDREAZZA, 2001). 
Assim, por quase um século existiram somente as duas vilas no Paraná e "tudo o que estivesse além da serra para o sertão era de Curitiba, e o que ficasse para baixo, até a costa da marinha era da vila de Paranaguá”. (SANTOS, 1951, p. 34). Neste período, não havia estrutura de sociedade, conforme o modelo atual. O Paraná se constituía de uma sociedade mais rural, de pessoas que viviam com muita simplicidade, trabalhavam na roça e se sustentavam do que produziam. Na época não existiam postos de saúde, nem hospitais, nem escolas, muito menos bibliotecas. Novas divisões territoriais só vieram a acontecer em meados do século XVIII, quando a coroa portuguesa iniciou a contabilização sistemática dos habitantes. Em 1772, moravam no Paraná 4.245 pessoas, entre trabalhadores da lavoura e uma pequena porcentagem eram recrutas militares que atuavam nas expedições aos sertões do Tibagi e Campos de Guarapuava (TRINDADE; ANDREAZZA, 2001).

No Paraná, assim como em todo território nacional, foi a Companhia de Jesus que obteve a permissão e mantinha a missão de instrução, ou seja, a licença para manter as aulas de ler, escrever e contar em seus colégios primários. Foram os Jesuítas que trouxeram os primeiros livros que eram utilizados em seus colégios para o ensino dos meninos e aperfeiçoamento dos mestres, de acordo com Trindade e Andreazza (2001, p. 33-34):

Efetivamente, foi na capela de Nossa Senhora das Mercês de Paranaguá que funcionou a primeira escola primária no Paraná entre os anos de 1708 e 1741, fundada e mantida pelos padres Jesuítas. O segundo Colégio implantado, foi o Jesuíta da Ribanceira e nele concentraram-se as atividades educacionais até 1759.

Nesse ano, ocorreu a expulsão dos Jesuítas do Brasil, com isso, a desestruturação das práticas educacionais, fechamento dos colégios jesuíticos, e os livros que eram utilizados pelos padres para ministrar as aulas, se perdem e inicia um novo período com as licenças para os professores ministrar atividades pedagógicas em suas casas. Nesta nova estrutura de ensino, "não havia livros impressos em uso nessa escola. Algumas páginas manuscritas eram usadas em lugar de livro e leitura [...] e raramente possuíam uma página que seja de material impresso, sendo usada para aula de leitura, carta escrita por comerciante" (HALLEWELL, 1985, p. 207).

Assim, a Quinta Comarca de São Paulo ficou desprovida do acesso à educação, aos livros e à leitura. A estrutura no período Jesuítico se perdeu e as bibliotecas escolares ainda estavam longe de serem pensadas e estruturadas, visto que poucos eram os espaços destinados à educação. Além dos Jesuítas que foram expulsos, outras ordens como os beneditinos, carmelitas e franciscanos mantinham alguns espaços educacionais, mas por falta de eficiência, permaneceram por pouco tempo na região (TRINDADE; ANDREAZZA, 2001). 
Em 1770 é instalada, formalmente no Brasil, a primeira escola régia, sendo cobrado o subsídio literário em alguns produtos para investir na educação, mas "os professores geralmente não tinham preparação para a função, já que eram improvisados e mal pagos. Eram nomeados por indicação ou sob concordância de bispos e se tornavam "proprietários" vitalícios de suas aulas régias" (BELLO, 2001, p. 1).

Na Quinta Comarca inicia-se uma verdadeira busca por mestres régios, pois nosso Estado estava totalmente desprovido da educação pública, somente quem possuía condições financeiras, poderia usufruir de aulas particulares e, nesse contexto, estaria privado de ter acesso a bibliotecas. De acordo com Miguel (1997, p. 677):

A partir de 1825 parece haver, por parte do governo central, a preocupação em organizar o ensino nas províncias. Assim, naquele ano, pela decisão de 26 de fevereiro, o governo pedia, às províncias, informações sobre a instrução pública para que pudesse tomar medidas, a fim de melhorar por todo o Império os meios de instrução, segundo as particularidades de cada povoação.

Dessa forma, pretendia-se que cada província, vila ou comarca tivesse uma escola pública de ensino primário, gratuita, com acesso aos bens culturais ao livro e à leitura. A intenção era educação e cultura como empreendimento do estado (LOURENÇO FILHO, 1944), embora houvesse empenho e tentativas, planos e ideias para o desenvolvimento do ensino, disseminação do livro e consequente implantação de bibliotecas escolares e populares, pouco foi feito. De acordo com Trindade e Andreazza (2001, p. 47):

Foi apenas com a lei de 15 de novembro de 1827 , considerada a primeira lei orgânica da instrução nacional, que o Império oficialmente regulamentou a educação da nova nação. Com pequenas alterações em virtude do Ato Adicional de 1834, que transferiu as províncias o poder de legislar sobre o ensino primário reservando-se ao poder central o direito de dispor sobre o ensino secundário e superior.

Assim, criaram-se duas cadeiras de primeiras letras nas vilas de São José dos Pinhais e em Palmeira (TRINDADE; ANDREAZZA, 2001) e, aos poucos, foram chegando mais professores para as demais vilas da Quinta Comarca. Entretanto, as bibliotecas escolares estavam longe de serem pensadas e efetivadas na Quinta Comarca da Província de São Paulo como parte integrante do sistema educativo e facilitadora do encontro com material bibliográfico e informacional aos educadores e educandos. 


\title{
Emancipação Política do Estado do Paraná
}

Em meados do século XIX, a população da Quinta Comarca iniciou o movimento de emancipação da província de São Paulo, que se concretizou em 19 de dezembro de 1853, pela Lei n. 704 de 29 de agosto, tendo Zacharias Goés de Vasconcellos como primeiro presidente (TRINDADE; ANDREAZZA, 2001). A situação educativa e cultural na nova província era precária:

\begin{abstract}
A legislação Paranaense caracterizou-se fundamentalmente por criar "cadeiras" de primeiras letras nos lugares mais desenvolvidos. A primeira Escola Normal foi criada pela lei $\mathrm{n}^{\circ} 238$ de 19 de abril de 1870 . Destinava-se a atender ambos os sexos e na legislação estavam definidas as matérias, a duração do curso e a idade mínima, entre outras exigências aos candidatos (MIGUEL, 1997, p. 680).
\end{abstract}

Neste período, havia apenas "615 alunos nos cursos de primeiras letras, numa população de 62.000 habitantes", conforme Trindade e Andreazza (2001, p. 61). O ensino secundário que era praticamente inexistente começou a desenvolver a partir da Lei $\mathrm{N}^{\mathrm{o}} .17$ de setembro de 1854, que criou na província as cadeiras de ensino secundário de latim, francês e inglês e, a partir desta lei, os ocupantes das cadeiras deveriam ser aprovados em concurso público (WERNECK, 1978).

Outro fator que contribuiu para o desenvolvimento do ensino secundário foi a criação do Liceo em, 1846, pela Lei $\mathrm{n}^{\circ} 33$, que funcionou até o final do século com a denominação de Instituto Paranaense, atuando em conjunto com a escola normal. Outros colégios secundários desenvolveram durante o império e alguns estabelecimentos de ensino funcionavam como internatos acolhendo a clientela do interior (TRINDADE; ANDREAZZA, 2001).

A Província do Paraná se desenvolvia em sua agricultura, mas as condições de ensino continuavam precárias. A população não tinha consciência da necessidade de escolarização e, muito menos, da leitura e das bibliotecas para seu crescimento. Neste sentido, analisamos o regulamento de ordem geral das escolas de instrução primária, preparação, organização do professorado, condições e normas para o ensino particular primário e secundário na Província, constatou-se que nada é referenciado à implantação e instalação de bibliotecas nas escolas, nem da importância e uso do livro no processo de ensino, para incentivo a leitura e para formação do cidadão.

Os alunos do Liceo sofriam com a falta de materiais e livros didáticos e literários, os poucos existentes eram adquiridos com dificuldade em São Paulo e no Rio de Janeiro (STRAUBE, 2006). De acordo com Straube (2006, p. 12), na província do Paraná: 
Histórico das bibliotecas escolares no Estado do Paraná

[...] nenhuma livraria, nenhuma biblioteca existia para atender aos alunos e professores. Era urgente a necessidade de ser criada na cidade que florescia e se expandia, um local adequado para a leitura e pesquisa dos clássicos da época e das ciências e artes, com o fim de alargar os conhecimentos.

Em 1855, o presidente Zacarias de Góes e Vasconcelos sentiu a necessidade de criar uma biblioteca na província, porém criar uma biblioteca em cada escola era algo utópico. Ainda hoje é frequente a existência de uma única biblioteca pública nas cidades do interior do Estado, ali cumprem o papel de biblioteca pública, escolar, infantil, juvenil etc.

A Lei $\mathrm{n}^{\circ} 27$ de 7 de março de 1857 autoriza a criar na capital da província uma biblioteca pública, anexa ao Liceo (STRAUBE, 2006), esta não era biblioteca escolar do Liceu, era pública anexa ao Liceu, mas pode ser considerado um avanço a criação deste espaço que seria o berço do conhecimento e cultura na província.

Em 19 de abril de 1870, o presidente da província Antônio Luiz Affonso de Carvalho, pela Lei $\mathrm{N}^{\circ}$. 238 decreta a instituição de uma escola normal para o ensino das pessoas de ambos os sexos que quisessem exercer o professorado da instrução elementar, também não há menções sobre a metodologia de ensino, nem adoção de livros e nem uso de bibliotecas como suporte ao ensino (WERNECK, 1978).

Em 12 de abril de 1876 pela Lei no .456 , o presidente da Província recebe autorização para reformar o regulamento de instrução pública, assim criam-se mais cadeiras de gramática, latim, geografia, alemão, história, filosofia, aritmética e álgebra. Os ocupantes das cadeiras assumiam o cargo por nomeação, independente de concurso. Nesta mesma lei também é criado um conselho literário, porém não há menções a livros, leitura e bibliotecas e quanto ao conselho criado não há documentos, nem relatórios sobre sua ação e atividades desenvolvidas (WERNECK, 1978).

Em 26 de outubro de 1877 surgiu o primeiro documento com menção específica à criação de uma biblioteca escolar no período imperial. Trata-se de uma correspondência interna do governo que apresenta a instalação e inauguração de uma biblioteca escolar em Curitiba, capital da província, sendo implantada e utilizada como suporte nas aulas da primeira cadeira do sexo masculino (PARANÁ, 1877). Nota-se, então, o primeiro avanço do Estado do Paraná em relação às bibliotecas escolares, pois se pensou no espaço específico para guarda e uso dos livros e para momentos de leitura, embora fosse apenas direcionado à capital da província.

No entanto, ao final do Império, a Província do Paraná ainda tentava reformular e 
estruturar o ensino público e, em novembro de 1882, pela Lei n. ${ }^{\circ} 712$ extinguia o Instituto Paranaense (antigo Liceu), reorganizava a escola normal e criava as escolas primárias. Na última década do Império, "a província do Paraná, publicou o regulamento que tornava o ensino obrigatório e previa sanções penais aos que não cumprissem a obrigatoriedade do ensino" (MIGUEL, 1997, p. 680). No entanto, analisando cartas e correspondências internas do governo da época, disponíveis no Arquivo Público do Paraná, percebe-se que a teoria difere da realidade, pois neste período foram construídas escolas, mas a falta de professores impedia a maioria da população de ter acesso à escolarização e à leitura.

Em 21 de setembro de 1884, data o segundo documento do governo do Estado do Paraná, uma correspondência interna, que mostra a preocupação do governo provincial com a criação de biblioteca escolar modelo, numa escola da capital da província. Neste documento o governo solicita a ajuda do nobre Abílio César Borges, o barão de Macahubas, para implantação de uma biblioteca numa escola que seria modelo em nossa província. O barão apreciou os desejos do governo, que se preocupava com o desenvolvimento e aperfeiçoamento do ensino, mais do que a ajuda financeira, o barão faz doação a Província do Paraná de obras especiais sobre educação e 5000 exemplares de compêndios escolares para serem distribuídos aos que frequentam as escolas (PARANÁ, 1884).

Ainda que se apresentasse de modo tímido, quase uma década depois do primeiro documento da província a indicar a biblioteca escolar, iniciou-se outra fase para a consolidação dessa instituição e a preocupação recaiu no acervo, no número de volumes para sua composição e na diversificação dos títulos, para melhor atender pedagogicamente a unidade escolar a qual pertencia.

Ao fim do período imperial havia muitas reflexões acerca das reformas educacionais, na difusão de novos métodos de ensino e de alfabetização, que buscavam conciliar o ensino da leitura e da escrita, bem como a propagação das bibliotecas escolares e a criação do Museu Pedagógico (SCHUELER; MAGALDI, 2009), porém na prática a realidade foi diferente, nada aconteceu.

A exemplo do que ainda ocorre atualmente, embora existissem indicações governamentais para a implantação da biblioteca escolar, no entanto, a educação caminhava precariamente, esta não era a prioridade da época. Não existiam efetivamente escolas públicas, com salas de aula, bibliotecas etc., foi somente com a mudança do regime político é que inicia uma preocupação maior com a formação do cidadão. 


\section{Biblioteca Escolar no Paraná: Período Republicano}

Com a proclamação da República no Brasil, em 1889, “de inspiração positivista, buscou uma nova estruturação social procurando romper com aquela vinculada ao Império, considerada arcaica, e trazer parâmetros modernos ao País" (CASTRO, 2009, p. 124). O novo discurso republicano era que "a instrução primária deveria ser obrigatória, universal e gratuita. Acreditava-se, portanto, que, por meio da educação, sobretudo a popular, o Brasil poderia superar o seu atraso econômico e cultural" (CORREIA, 2004, p. 87).

Neste contexto, a instrução pública assumiu maior importância na sociedade republicana e de acordo com Castro (2009, p. 124):

Uma das principais ações no período foi a sistematização do ensino primário, estruturado na criação de grupos escolares e no estabelecimento de um novo programa de ensino: a escola graduada ou seriada. A introdução de novos métodos, racionalização e padronização do ensino - permitindo a classificação dos alunos por série, a divisão do trabalho docente e a profissionalização do magistério.

Iniciam-se discussões e reflexões acerca da construção de prédios escolares padronizados com ambientes que iam além das salas de aula. Assim, surgem os grupos escolares, com "espaços funcionais que a nova pedagogia da época exigia: gabinete para diretor, bibliotecas, secretarias, oficinas, pátios [...]" (CORREIA, 2004, p. 12). Estas discussões e preocupações garantiram na arquitetura dos grupos escolares, espaços específicos para as bibliotecas escolares e salas de leitura.

Antes da inauguração do primeiro grupo escolar, havia em Curitiba somente três escolas públicas de ensino primário. Para o atendimento das meninas havia a Escola Tiradentes e a Escola Carvalho e, para os meninos, a Escola Oliveira Bello (BENCOSTTA, 2001); e nos documentos analisados não há menção a bibliotecas ou sala de leitura nestas escolas. Oficialmente a primeira menção à existência de biblioteca na escola no Estado do Paraná deu-se no período republicano devido às novas exigências pedagógicas do período. De acordo com Castro (2009, p. 127):

O número de escolas brasileiras cresceu significativamente durante a República. No Paraná, essa situação repetiu-se, surgindo no cenário urbano importantes edifícios escolares públicos, que se tornaram marcos do período. Logo nos primeiros anos do século 20, no aniversário de 50 anos da criação da Província do Paraná, em 19 de dezembro de 1903, foi inaugurado em Curitiba o Grupo Escolar Dr. Xavier da Silva, destinado à instrução primária. Nos anos seguintes, foram construídos três edifícios escolares: o Grupo Escolar Vicente Machado, em Castro, o Cruz Machado, em Curitiba, e o Jesuíno Marcondes, em Palmeira.

Com a implantação do primeiro código de ensino do Estado do Paraná, aprovado 
através da Lei $N^{\circ} .710$, de 18 de outubro de 1915, criam-se os conselhos de educação estadual e local, amplia-se a biblioteca pública estadual e muitas outras escolas foram construídas e se disseminando nas mais diversas cidades do Estado (WERNECK, 1978).

As plantas arquitetônicas dessas instituições de ensino, do início do século XIX, já contavam com espaços para as bibliotecas escolares. Durante a Primeira República, 36 edifícios destinados à instrução primária foram construídos. Entretanto, até 1928, somente duas escolas dispuseram de todos esses espaços exigidos: bibliotecas, laboratórios etc. Os grupos escolares contemplados com as salas específicas foram: o Grupo Escolar Dr. Xavier da Silva (1903) e o Grupo Escolar D. Pedro II, em 1929, conforme Correia (2004), o que demonstra que, nesta época, o Paraná ainda enfrentava dificuldades em relação à sistematização de uma nova estrutura de ensino, bem, como a compreensão de que os livros e a leitura têm um papel fundamental na formação de cidadãos críticos.

Neste período já havia em nosso Estado os colégios religiosos, as irmãs da congregação de São José de Tarentaise e os Irmãos Maristas, ambos da França. A congregação das irmãs implantou e manteve várias escolas nas diversas cidades do Paraná, “colégios esses, que representaram o escol da intelectualidade na capital" (WERNECK, 1978, p. 71). Os Maristas fundaram o Instituto Santa Maria que funciona até os dias atuais com ensino primário, secundário, maternal, jardim e pré-escola, possui uma biblioteca exemplar com livros atualizados disponíveis a toda comunidade escolar (WERNECK, 1978), mas em documentação analisada não há menções à implantação de bibliotecas escolares na época em que iniciaram os seus trabalhos educativos no Paraná.

Em 1932, acontece em nosso país o manifesto dos pioneiros para uma escola nova, orientados por novos princípios educacionais. De acordo com Werneck (1978) o movimento Escola Nova iria orientar-se pelos seguintes princípios:

1. Maior liberdade para a criança, a que se pretende proporcionar condições mais favoráveis ao seu desenvolvimento natural, pela atividade livre e espontânea;

2. O principio de atividade (métodos ativos, escola ativa) ligado ao da liberdade e inspirado no pensamento de que a criança é um ente essencialmente ativo, cujas faculdades se desenvolvem pelo exercício;

3. O respeito da originalidade de cada criança, e em consequência a individualização do ensino, sob o fundamento de que a cada um é devida a educação que lhe convém. 
No Paraná, secretário da educação na época, o professor Erasmo Carlos, estabeleceu diretrizes e abriu mais de 1000 escolas na zona rural, ampliou a rede de ginásios com 25 novas unidades, criou mais de 20 cursos normais, destinados à formação de professor (WERNECK, 1978), mas nos documentos oficiais analisados nada consta acerca do uso das bibliotecas e dos livros no processo de ensino.

Desde a década de 1940, Ferraz defendia a importância da biblioteca na escola afirmando que "não há parte mais importante, hoje em dia, na administração escolar, que a administração de uma biblioteca, pois é em torno dela que gira todo interesse da escola moderna. Sem ler não é possível iniciar nenhuma obra de educação” (FERRAZ, 1957, p.125). A autora enfatiza em suas escritas que a Escola Nova baseava na autoatividade do aluno, na sua capacidade intelectual e que, para isso, era imprescindível o uso da biblioteca. De acordo com Ferraz (1957, p. 127-128):

A escola que não da à criança o gôsto pela leitura, não ensina a ler. É na biblioteca escolar que este gôsto vai despertar, e não apenas aprendendo os textos, na classe. [...]. A biblioteca tornou-se uma parte indispensável da escola, tendo em vista a tendência para adotar, cada vez mais, os métodos progressivos.

A autora defende a biblioteca como um local que deve ser privilegiado dentro da escola, como um espaço de promoção à leitura, próprio para o encontro do aluno com o livro, com a literatura.

Em 1945, com a redemocratização do Brasil, iniciam-se debates acerca da política educacional do país e em dois de janeiro de 1946 é decretada a Lei no 8.529 (BRASIL, 1946) com objetivo de fixar as bases e diretrizes para o ensino, porém constituía uma quase renúncia do Estado ao ensino público, o que fez os educadores se posicionassem contrários ao projeto de lei, que foi aprovado em 20 de dezembro de 1961, com a lei 4024 denominada Lei de Diretrizes e Bases da Educação Nacional (WERNECK, 1978).

Este Projeto não foi discutido, debatido com educadores e especialistas da área, pois foi, praticamente, imposto pelo governo e como nas leis anteriores, nada consta acerca do uso das bibliotecas nas escolas, sua importância como instrumento de apoio no processo de ensinolaprendizagem e na formação do leitor. Por um lado, visualizam-se escritores defendendo as bibliotecas escolares e, por outro, um governo autoritário que não reconhece e efetiva importância desses espaços no ambiente escolar.

Paralelo às leis educacionais, ocorre neste período um aumento na produção literária para crianças e adolescentes. De acordo com Silva (2008, p. 3): 
A partir dos anos 50/60 expandiu-se consideravelmente a rede escolar e de lá para cá o mercado editorial para este público leitor. Na segunda metade dos anos 70 temos o aparecimento e o fortalecimento progressivo de uma nova geração de escritores para crianças e jovens, com uma produção literária nova, que será cada vez mais abundante, diversificada e também heterogênea. Lado a lado com os já conhecidos livros escolares e séries didáticas (e, muitas vezes, fazendo sua crítica) essa produção coloca-se desde então para a escola, com maior ênfase.

Por um lado visualiza-se o aumento da produção literária voltado para o público escolar e, por outro, visualiza-se no Estado a falta de legitimação das bibliotecas nas escolas. As bibliotecas escolares não recebem a devida atenção e importância por parte das autoridades e governantes, diante desta situação e de acordo com Silva (2008, p. 6), foram criadas em nosso Estado:

Os acervos de classe que foram imaginados para funcionarem como complemento ou como substitutos das bibliotecas escolares, até mesmo como via de superação de um obstáculo, insistentemente levantado pelos professores, que era a inexistência da biblioteca na escola ou a dificuldade em se poder utilizá-la.

Estes acervos eram uma alternativa que contribuíram para o incentivo à leitura $\mathrm{e}$ também como suporte aos professores em sala de aula até que bibliotecas fossem instaladas em todas as escolas, o que não acorreu até nossos dias, pois até hoje há muitas escolas sem biblioteca escolar.

Em resposta a Lei n 4024 (Diretrizes e Bases da Educação Nacional), em três de julho de 1962, cria-se no Paraná, o Fundo Estadual de Ensino e a Fundação Educacional do Paraná - FUNDEPAR, pela Lei no ${ }^{\circ}$ 7253, com objetivo de gerir os recursos do Fundo Estadual de Ensino, porém nada consta sobre investimentos em bibliotecas, livros ou salas de leitura.

Iniciam-se sérias discussões acerca do currículo e programas de ensino em nosso estado, até que em 1967, no governo Paulo Pimentel, a Secretaria de Educação e Cultura, chefiada por Carlos Alberto Moro, lança o documento "O ensino primário no Paraná: programas para as escolas primárias do estado". Este documento, além dos objetivos, traz os hábitos e atitudes que os professores devem desenvolver nos alunos. De acordo com análise do documento, entre as atitudes, algumas merecem destaque, como:

Procurar sempre usar o livro e outras fontes de informação [...] Proporcionar domínio da técnica oral desembaraçada [...] Despertar o amor pela leitura [...] Tornar a criança capaz de ler, de interpretar o que leu, pela ação, por palavras próprias [...] Despertar o interesse por autores nacionais [...] Pesquisar, usando fontes de informação [...] Desenvolver o interesse pela boa literatura e pela leitura de material variado, com a finalidade de recreação e informação (PARANÁ, 1967, p. 11).

Embora estes itens estejam relacionados à ação da biblioteca escolar, não há referência específica a ela, bem como sua função no desenvolvimento das habilidades acima citadas e de 
sua contribuição para o processo de ensino-aprendizagem.

Em 1971 com a Lei $n^{\circ} 5.692$, é aprovada uma nova reforma dos ensinos de $1^{\circ}$ e $2^{\circ}$ graus. A maioria dos artigos da Lei $\mathrm{n}^{\circ} 4.024$ foram revogados, alguns permaneceram e outros implementados e, estes, trouxeram grandes inovações, uma delas foi referente à pesquisa escolar, que se tornou obrigatória nas escolas públicas de ensino fundamental e médio (NISKIER, 1995), mesmo com a mudança da lei, não há menção à biblioteca escolar.

No Estado do Paraná a primeira legislação que define "a obrigatoriedade das escolas de $1^{\circ}$ e $2^{\circ}$ graus manterem bibliotecas foi a deliberação 02/72 e a deliberação $030 / 80$ do Conselho Estadual de Educação do Estado do Paraná e resolução no 2.581/81 da SEED” (PARANÁ, 1989, p. 5). Estas deliberações em nada repercutiram a prática das bibliotecas escolares, pois até hoje, muitas escolas estão sem espaços para implantação da biblioteca.

Na década de 1980 o Estado do Paraná, em resposta a implantação do projeto federal salas de leitura, criou o projeto "Os livros criam asas". Este projeto chegou como uma ação viva no fomento à leitura no Estado, os livros eram enviados para sala de aula através de sacolas-estante em horários pré-agendados ou no término das tarefas ou quando faltava um professor. A criança tinha a liberdade de escolher o livro e a leitura era feita de forma individual e silenciosa, não havia cobrança, provas e trabalhos acerca da leitura efetuada, o foco era somente a leitura em si. (MARTELLI, 1995). Ainda de acordo com a autora, as diretrizes que nortearam o projeto foram:

a) facilitar o trânsito do livro literário na escola de $1^{\circ}$ grau pela adoção do mecanismo de acondicionamento dos acervos em sacolas-estante e, por conseqüência, pelo instituto de uma biblioteca alternativa volante. Tal biblioteca, sem a pretensão, jamais, de erradicar ou substituir a biblioteca convencional, teria um papel, a médio e longo prazo, de influir na dinamização dessa última (MARTELLI, 1995, p. 54-55).

O projeto foi uma tentativa de democratizar o acesso ao livro, à leitura e à literatura infantil nas escolas e durou cerca de cinco anos, de 1985 a 1990 e de acordo com Martelli (1995, p. 54):

[...] atendeu, de 1985 a 1987, 6.082 escolas pertencentes às redes estadual e municipal de ensino, situadas em 153 municípios pertencentes a 12 Núcleos Regionais de Ensino e, de 1988 a 1990, na última etapa da implantação, apenas escolas da rede estadual, num total de 836, localizadas em 79 municípios, pertencentes a 5 Núcleos Regionais de Ensino. Foram distribuídos, no Paraná, 564.369 exemplares de literatura infanto-juvenil beneficiando, aproximadamente, 1.100.000 alunos do $1^{\circ}$ grau da rede pública.

Este projeto foi um marco importante para o incentivo à leitura dentro das escolas 
paranaenses. Os alunos ganharam um momento específico para a leitura, para o contato com o livro. A iniciativa era tímida, mas promovia a leitura, contribuindo para a formação da competência leitora dos alunos.

Na década de 80, mais especificamente em 1983, acontece a primeira tentativa de instituir no Estado do Paraná um trabalho em rede com as bibliotecas escolares. Neste período, cria-se a Comissão Estadual do Livro e iniciam reflexões para a implantação do SIBEPAR - Sistema de Bibliotecas Escolares do Paraná, com objetivo de estruturar bibliotecas, deixá-las dinâmicas, nos estabelecimentos de ensino do estado, a fim de satisfazer as necessidades didático-pedagógicas das escolas.

O primeiro projeto de implantação do SIBEPAR foi elaborado sob consultoria da professora Dra ${ }^{\mathrm{a}}$. Graça Maria Simões Luz, do departamento de biblioteconomia da Universidade Estadual de Londrina, com a colaboração das professoras Ivone Guerreiro Di Chiara e Yara Maria Pereira da Costa Prazeres, ambas as professoras do departamento de biblioteconomia da UEL (PARANÁ, 1989, p.1). De acordo com o projeto SIBEPAR:

Considera-se que a implantação de um Sistema de Bibliotecas escolares no Paraná, estruturado sob forma de rede, é o meio mais adequado e oportuno para a solução do problema referente à situação das bibliotecas escolares, integrando-as definitivamente no processo ensino-aprendizagem (PARANÁ, 1989, p. 6).

Entre os objetivos do projeto SIBEPAR, destaca-se: a implantação de bibliotecas escolares com infraestrutura necessária para o cumprimento de todos os seus objetivos; ampliar os serviços bibliotecários, favorecendo a formação integral dos estudantes; normalizar os procedimentos técnicos de organização e funcionamento das bibliotecas; promover a formação e desenvolvimento do gosto pela leitura e pesquisa (PARANÁ, 1989).

A ideia de implantar o Sistema de Bibliotecas era adequada, porém por estar condicionado a decisões políticas do Estado com investimentos financeiros e recursos humanos, o projeto ficou engavetado por muitos anos, totalizando oito tentativas de implantação e nenhum sucesso.

Assim, enquanto o Estado do Paraná lutava pela implantação da rede de bibliotecas escolares, em nível municipal, na cidade de Curitiba, na década de 1990, houve a implantação dos "Faróis do Saber", com isso, a Secretaria Municipal de Educação tinha o seguinte lema "Vamos erguer a cidade tendo livros por armas e faróis por sentinelas". Os faróis do saber são bibliotecas comunitárias, situadas nas escolas municipais, que não possuíam bibliotecas escolares ou em espaços públicos. "Pretende-se basicamente congregar a leitura - ato 
principal do conhecer, com programação de atividades que priorizem a pesquisa, a criatividade, a reflexão, o interesse e o gosto de frequentar uma biblioteca como instrumento para a compreensão do mundo" (CURITIBA, 1994, p. 6).

De acordo com a Secretaria Municipal de Educação de Curitiba, os objetivos da implantação dos faróis do saber são:

\begin{abstract}
Oportunizar o acesso aos bens culturais, resgatando o fenômeno literário e o prazer do texto; Criar condições que favoreçam a prática da leitura, pesquisa, informação e reflexão, instrumentos para a formação e o exercício da cidadania; [...] Suprir as bibliotecas de livros, periódicos e bens culturais, tendo em vista o interesse e as expectativas dos usuários (CURITIBA, 1994, p. 8).
\end{abstract}

Em 1994, no primeiro ano do projeto, 12 escolas foram contempladas com os Faróis do Saber, atualmente há 45 faróis e, destes, 34 estão dentro das escolas, os outros funcionam em praças públicas (CURITIBA, 1994).

Apesar de legislações anteriores, é somente na década de 90 que efetivamente iniciaram-se as pequenas conquistas em prol das bibliotecas nas escolas, dos livros e da leitura como instrumento de produção de conhecimento e prazer.

Em meados da década de 90 é decretada a atual Lei nº. 9394/96, de Diretrizes e Bases da Educação Nacional, porém, após análise dos seus artigos, constatamos não haver referências à biblioteca escolar, função, contribuição ao processo de ensino-aprendizagem. Uma lei como esta deveria assegurar e garantir o espaço das bibliotecas nas escolas, para leitura, pesquisa, recreação, produção de conhecimento e cultura. Para Silva (1991, p. 112) "a biblioteca escolar deve ser um recurso básico para as decisões curriculares, permitindo a atualização pedagógica dos professores, a aprendizagem significativa dos estudantes e a participação da comunidade".

Após análise das diretrizes da educação nacional, iniciou-se análise dos Parâmetros Curriculares Nacionais (PCNs) e estes enfatizam a importância das escolas disporem de boas bibliotecas que atendam as necessidades para o desenvolvimento do gosto pela leitura (BRASIL, 2001, p. 81):

\footnotetext{
As bibliotecas escolares têm papel fundamental no sucesso desse trabalho de iniciação literária e de formação do gosto. É preciso que existam, que tenham acervos significativos, que estejam disponíveis para todos, que o acesso ao livro seja direto, que as técnicas biblioteconômicas de catalogação e armazenagem dos livros sejam adequadas a leitores em formação e sejam a eles explicadas, quando necessário, mais importante que tudo talvez, é que a escola crie, como parte de suas atividades regulares, demandas autênticas de leitura, capazes de fazer da biblioteca um lugar de freqüência.
} 
Neste contexto, esse período no Estado do Paraná acentuam-se as discussões e reflexões quanto à importância e papel das bibliotecas escolares, implantação, funcionamento, serviços etc. Diante disso, o Município de Curitiba implantou o Sistema Municipal de Bibliotecas Escolares. A rede municipal de bibliotecas escolares de Curitiba foi instituída pelo decreto no 376 de 17 de abril de 2007, cujo conteúdo da redação é o seguinte:

Art. 1: Fica constituída, junto à secretaria municipal de educação, a rede municipal de bibliotecas escolares de Curitiba, com a finalidade de servir de suporte a programas de educação, integrando-se aos processos educativos das instituições de educação e ensino.

Art. 2: A rede municipal de bibliotecas escolares de Curitiba compreende:

Bibliotecas escolares em funcionamento e as que serão implantados pela secretaria municipal da educação e integradas ao prédio da escola;

Bibliotecas "faróis do saber" subordinadas a secretaria municipal de educação;

Bibliotecas construídas em parcerias;

Biblioteca Virtual (PARANÁ, 2007, p. 6).

Após várias tentativas sem sucesso, este decreto foi um grande avanço para a cidade de Curitiba. Sabe-se que as bibliotecas escolares são fundamentais no processo de ensinoaprendizagem e para formação de todo e qualquer cidadão.

Esta rede vem com a proposta de democratizar o acesso ao conhecimento à população curitibana e, para que isso ocorresse com excelência, realizou-se um diagnóstico sobre a realidade das bibliotecas escolares, dos Faróis do Saber e de todas as bibliotecas que fariam parte deste Sistema de Bibliotecas da Cidade de Curitiba. Em análise a este documento, visualiza-se que a:

Biblioteca e escola têm uma história de avanços e recuos com várias propostas,
mudanças de políticas e idéias. O decreto n 336 , de 24 de junho de 1976 , instituiu a
biblioteca central e bibliotecas nas unidades escolares do departamento de bem estar
social da prefeitura municipal de Curitiba. A partir daí, surgiram, ao longo do
tempo, várias outras propostas: 1978 , projeto de implantação de módulos de
bibliotecas nas escolas municipais de Curitiba; 1980 bibliotecas escolares
comunitárias; 1983 rede de bibliotecas municipais; 1984 salas de leitura e centro de
atividades criativas; 1989 biblioteca volante para classes de ensino supletivo; 1990
sala de leitura volante; 1991 bibliotecas escolares; 1994 faróis do saber (CURITIBA,
2005, p. 3).

Percebemos que além da tentativa de implantação do SIBEPAR, várias outras tentativas ocorreram, porém nenhuma delas obteve o sucesso da estruturação e continuidade. Talvez pela falta de recursos financeiros ou pela falta de apoio político, somente em 2005 obteve-se sucesso com a sistematização das bibliotecas escolares municipais em rede.

Em 2010, realizou-se um diagnóstico com orientações para implantação de biblioteca escolar em todas as escolas do Paraná, pertencentes à rede estadual de ensino, era uma 
tentativa de se olhar mais reflexivamente para as bibliotecas escolares em nível estadual, culminando na estruturação de um sistema em rede.

O discurso do estado apresenta gradativa mudança, pois propõe que as bibliotecas escolares "extrapolem a função de guarda, organização e consulta a acervos, tornando-as espaços de formação de leitores" (PARANÁ, 2010, p.10). O diagnóstico realizado aborda a questão do acervo, dos móveis, dos equipamentos, das instalações físicas, da equipe de trabalho, do software a ser utilizado, dos projetos a serem desenvolvidas etc. Constatamos que toda uma avaliação foi realizada antes da escrita da aprovação do projeto que aconteceu em 2011 (PARANÁ, 2010).

Em fevereiro de 2011 é apresentado o projeto de implantação do Sistema da Rede de Bibliotecas Escolares Públicas Estaduais que tinha como principal objetivo "legalizar, implantar, consolidar o Sistema de Bibliotecas Escolares Públicas da Rede Estadual de Ensino do Paraná” (PARANÁ, 2011), cujos principais objetivos são:

\footnotetext{
Garantir o funcionamento efetivo do espaço destinado à biblioteca em conformidade com a lei Federal 12.244, de 24/05/2010, que dispõe sobre a universalização das bibliotecas nas instituições do país;

Garantir a implantação do sistema;

Padronizar todas as bibliotecas escolares já existentes, com novos acervos, reforma e ampliação adequando-as a Resolução SESA 0318/2002 (se for caso) que dispõe sobre Normas Técnicas para as instituições de ensino fundamental, médio e superior que compõem o Sistema Estadual de Ensino. Respeitando-se as especificidades e diversidades regionais e locais de comunidades isoladas, colônias, distritos, entre outras;

Adequar os espaços às pessoas portadoras de necessidades especiais, da criação de bibliotecas digitais em rede, programação de atividades culturais e serviços oferecidos ao desenvolvimento profissional dos indivíduos; Criar novos espaços de socialização e projetos culturais entre estudantes, docentes e comunidade;

Ofertar novos serviços adaptados às comunidades desde informação local, até a formação dos cidadãos pelo acesso a jornais, revistas, internet, livros, periódicos, etc., permitindo o surgimento de um leitor crítico.

Capacitar os funcionários que prestam serviços em bibliotecas da rede estadual, com formação, orientação e direcionamento especializado na área de biblioteconomia conforme deliberação (PARANÁ, 2011, p. 4).
}

Este projeto foi criado, inspirado no projeto da Prefeitura Municipal de Curitiba, e pretende atingir os 399 municípios do Estado do Paraná, criando bibliotecas nas escolas e estruturando as bibliotecas já existentes, atuando de acordo com a Lei nº 12244/2010 que visa universalizar as bibliotecas nas instituições de ensino em todo país. 


\section{Considerações finais}

No Estado do Paraná, assim como em quase todo território brasileiro, as bibliotecas escolares demoraram a ser constituídas e legitimadas perante a sociedade. Após a expulsão dos Jesuítas no século XVIII, a Quinta Comarca da província de São Paulo ficou totalmente desprovida do acesso à educação pública, aos livros, à leitura, à literatura e às bibliotecas.

No período de emancipação política, a situação educativa e cultural nesta nova província era precária, a população não tinha consciência da necessidade de escolarização e, muito menos, do uso de bibliotecas para seu desenvolvimento. Ao fim do período Imperial iniciam-se reflexões que buscavam conciliar o ensino da leitura e da escrita, bem como a propagação das bibliotecas escolares, porém, na prática, nada aconteceu.

Com a mudança do regime político e a reorganização do Estado, iniciou-se uma preocupação maior com a formação do cidadão, pois no período da República já se acreditava, que, por meio da educação, sobretudo a popular, o Brasil poderia superar o seu atraso econômico e cultural. Neste contexto, o número de escolas cresceu significativamente, devido às novas exigências pedagógicas do período, também, aumentaram as discussões a respeito da importância e da necessidade de biblioteca nas escolas, ampliou a produção literária voltada ao público escolar e neste período as bibliotecas nas escolas vão surgindo timidamente, sem a merecida atenção por parte das autoridades.

Nos dias atuais, o Paraná caminha para a estruturação de sistemas de bibliotecas em rede por todo o seu território, nos 399 municípios que compõe o Estado. Entretanto, ainda há muito que se fazer para que as bibliotecas escolares no Estado do Paraná exerçam de fato sua função na sociedade. Houve alguns avanços e garantias em Leis, mas é preciso avançar mais para que as bibliotecas exerçam de fato seu papel e função no ambiente escolar.

Vale ressaltar que as bibliotecas escolares são equipamentos fundamentais no processo de formação do leitor autônomo, crítico e reflexivo, além de contribuir no processo de ensinoaprendizagem, como apoio didático aos educadores e às pesquisas dos educandos. 


\section{Referências}

BELLO, José Luiz de Paiva. Educação no Brasil: a história das rupturas. Pedagogia em Foco, Rio de Janeiro, 2001. Disponível em: 〈http://www.pedagogiaemfoco.pro.br/heb14.htm>. Acesso em: 15 set. 2012.

BENCOSTTA, Marcus Levy. Arquitetura e espaço escolar: reflexões acerca do processo de implantação dos primeiros grupos escolares de Curitiba (1903-1928). Educar em Revista, Curitiba, n. 18, p. 103-141, jul./dez. 2001.

BRASIL. Ministério da Educação. Parâmetros curriculares nacionais de língua portuguesa para o ensino fundamental. Brasília: Ministério da Educação, 2001.

. Ministério da Educação. Secretaria de Educação Básica. Avaliação das bibliotecas escolares no Brasil. Brasília: Ministério da Educação, 2011.

BRASIL. Decreto-Lei no 8.529, de 2 de janeiro de 1946. Lei Orgânica do Ensino Primário. Disponível em: <http://www2.camara.leg.br/legin/fed/declei/1940-1949/decreto-lei-8529-2janeiro-1946-458442-publicacaooriginal-1-pe.html>. Acesso em: 15 nov. 2012.

CASTRO, Elizabeth Amorim de. A arquitetura dos grupos escolares do Paraná na primeira republica. Revista Brasileira de Pediatria, Brasília, v. 90, p. 122-148, jan./abr. 2009.

CORREIA, Ana Paula Pupo. História \& arquitetura escolar: os prédios escolares públicos em Curitiba (1943 - 1953). 2004. 179 f. Dissertação (Mestrado em História e Historiografia da Educação) - Universidade Federal do Paraná, Curitiba, 2004.

CURITIBA. Secretaria Municipal de Educação. Farol do saber. Curitiba, 1994.

Secretaria Municipal de Educação. Sistema de bibliotecas da secretaria municipal de educação: proposta de estruturação do sistema de bibliotecas da S.M.E. Curitiba, 2005.

FERRAZ, Wanda. A biblioteca. Rio de Janeiro: Livraria Freitas Bastos, 1957.

HALLEWELL, Laurence. O livro no Brasil: sua história. São Paulo: Ed. USP, 1985.

LOURENÇO FILHO, Manuel Bergstrõm. O ensino e a biblioteca: $1^{\text {a }}$ conferência da série educação e biblioteca. Rio de Janeiro: Imprensa Nacional, 1944.

MARTELLI, Clarice Lottermann. Leitura e escola: confronto e apreciação. 1995. $201 \mathrm{f}$. Dissertação (Mestrado em Letras - Literatura Brasileira) - Universidade Federal do Paraná, Curitiba, 1995.

MIGUEL, Maria Elisabeth Blanck. A legislação educacional paranaense e a história da educação (1821-1955). In: SEMINÁRIO NACIONAL DE ESTUDOS E PESQUISAS, 4., 1997, Campinas. Anais... Campinas: UNICAMP, 1997. Disponível em:

<http://www.histedbr.fae.unicamp.br/acer_histedbr/seminario/seminario4/apresentacao.htm>. Acesso em: 10 set. 2012. 
NISKIER, Arnaldo. Educação brasileira: 500 anos de história. Rio de Janeiro: Consultor, 1995.

PARANÁ. Governo do Estado. Correspondência do governo. Curitiba: Arquivo Público, 1877. v. 19, PB001, AP. 529, p.124.

Governo do Estado. Correspondência do governo. Curitiba: Arquivo Público, 1884, v. 19, PB001, AP 721, p.138.

. Governo do Estado. O ensino primário no Paraná: programa para as escolas primárias do estado. Curitiba, 1967.

. Governo do Estado. Orientações para organização e implementação das bibliotecas escolares. Curitiba: SEED, 2010.

. Governo do Estado. Projeto: implementação do sistema da rede de bibliotecas escolares públicas de Curitiba. Curitiba: SEED, 2011.

. Governo do Estado. Decreto 276 que institui a Rede Municipal de Bibliotecas Escolares de Curitiba. Curitiba, 2007.

Secretaria de Estado de Educação. Sistema de bibliotecas escolares do Paraná -

SIBEPAR: proposta de implantação. 1989. 32 f. Projeto (Projeto apresentado à Comissão Estadual do Livro da Secretaria de Estado), Curitiba, 1989.

SANTOS, Antonio Vieira. Memória histórica da cidade de Paranaguá e seu município: 1850. Curitiba: Museu Paranaense, 1951.

SCHUELER, Alessandra Frota Martinez; MAGALDI, Ana Maria Bandeira de Mello. Educação escolar na Primeira República: memória, história e perspectivas de pesquisa. Tempo, Niterói, v. 13, n. 26, 2009. Disponível em:

<http://www.scielo.br/pdf/tem/v13n26/a03v1326.pdf >. Acesso em: 15 nov. 2012.

SILVA, Ezequiel Theodoro. De olhos abertos: reflexões sobre o desenvolvimento da leitura no Brasil. São Paulo: Ática, 1991.

SILVA, Lílian Lopes Martin. Leitura na escola: livro, biblioteca, biblioteca de classe. 2008. Disponível em: <http://www.fe.unicamp.br/alle/textos/LLMS-Bibliotecadeclasse.pdf>.

Acesso em: 10 jan. 2013.

STRAUBE, Ernani Costa. Biblioteca Pública do Paraná: sua história. Curitiba: Imprensa Oficial, 2006.

TRINDADE, Etelvina Maria de Castro; ANDREAZZA, Maria Luiza. Cultura e educação no Paraná. Curitiba: SEED, 2001.

WERNECK, Maria da Luz Portugal. História da educação no Paraná. Curitiba: Executive, 1978. 